ВЗГЛЯД ИСТОРИКА:

ИСТОЧНИКОВЕДЕНИЕ И ИСТОРИОГРАФИЯ

УДК 93/94

ББК 63.3(2)

\title{
Е.А. ОБЕРНИХИН
}

\section{УВЕКОВЕЧЕНИЕ ПАМЯТИ О СОВЕТСКИХ ВОИНАХ, ПОГИБШИХ ПРИ ОСВОБОЖДЕНИИ ЕВРОПЕЙСКИХ СТРАН ОТ НАЦИЗМА В ГОДЫ ВЕЛИКОЙ ОТЕЧЕСТВЕННОЙ ВОЙНЫ (1944-1991): РЕЗУЛЬТАТЫ ПРОВЕДЕННОГО ИССЛЕДОВАНИЯ}

Ключевые слова: Великая Отечественная война, Красная армия, Центрально-Восточная Европа, память, результаты исследования, советские воинские захоронения.

Всестороннее изучение опыта государственных и военных структур по сохранению и уходу за воинскими могилами и местами памяти, о героических действиях Красной армии за рубежами России обретает все большую теоретическую значимость и практическую ценность. Целью данной статьи является обобщение результатов исследования, посвященного увековечению памяти о советских воинах, погибших при освобождении европейских стран от нацизма в годы Великой Отечественной войны (хронология событий 1944-1991 г2.). Специальных научных работ, комплексно рассматривающих деятельность официальных структур Советского Союза за рубежом, посвященных этой теме, нет. Методологической основой исследования стали современная теория познания общества, базирующаяся на концепции всеобщих связей в его социально-экономической, политической и культурной жизни, диалектический подход к анализу общественных явлений. Проанализированы различные аспекты проблемы с учетом непосредственной исторической обстановки, выявлены объективные закономерности, определявшие цели и содержание процесса сохранения памяти о погибших советских воинах, исследована деятельность официальных структур Советского Союза за рубежом по увековечению памяти о красноармейцах, погибших в годы Великой Отечественной войны при освобождении европейских стран от нацизма. В ходе исследования автором был решен ряд задач: исследована трансформация порядка персонального учета потерь личного состава в Красной армии; установлены особенности организации процесса погребения погибших и создания на территории европейских государств воинских кладбищ, а также уточнена существующая классификация воинских захоронений; установлены причины маситабной утраты имен красноармейцев, погибших при освобождении стран Европы от нацизма; определены основные этапы процесса укрупнения и сохранения советских воинских кладбищ, на территории европейских стран; проанализирован процесс создания мемориальных сооружений и объектов в странах Центрально-Восточной Европы и установлены 
его особенности; изучена реализация коммеморативных практик, фоормировавших в советское время историческую память об освободительной миссии Красной армии в европейских странах; установлены особенности межгосударственного взаимодействия по вопросам восстановления и сохранения советских воинских захоронений и памятников в европейских государствах; определена классификация процесса увековечения памяти о советских воинах в странах Центрально-Восточной Европы. Выполненное исследование позволяет утверждать, что именно в ходе укрупнения после войны советских воинских кладбищ произошла масштабная утрата имен погибших красноармейцев. Процесс создания мемориалов и обустройства воинских некрополей в европейских странах носил системный характер. Советским Союзом использовались различные коммеморативные практики, с помощью которых формировалась историческая память об освободительной миссии Красной армии в Европе.

На территории стран современной Европы, на полях сражений Великой Отечественной войны нашли свой покой миллионы наших соотечественников - солдат и офицеров Красной армии. Их одиночные и братские могилы напоминают современному поколению граждан Европы о том, какой ценой была достигнута победа над фашизмом в XX в., а нам, россиянам, дают право гордиться славой наших предков. В связи с попытками пересмотра итогов Второй мировой войны сохранение военных памятников и могил наших соотечественников, находящихся за пределами России, вызывает особую обеспокоенность государства и граждан нашей страны. Эффективно противостоять западным СМИ, искажающим события Великой Отечественной войны, можно только на основе результатов научных исследований событий прошлого. Таким образом, необходимы проведение комплексного исследования деятельности государственных и военных структур Советского Союза по увековечению памяти о воинах Красной армии, погибших в годы Великой Отечественной войны при освобождении европейских стран от нацизма, и его научное осмысление.

Научная новизна исследования заключена в том, что автором статьи были разработаны новые теоретические положения, совокупность которых можно квалифицировать как решение научной задачи, имеющей важное значение для дальнейшего развития исторической науки. Комплексного исследования исторического опыта деятельности официальных структур Советского Союза за рубежом по увековечению памяти о советских воинах не проводилось. В ранее защищенных диссертациях их авторы рассматривали процесс сохранения памяти о погибших советских воинах в контексте установления имен и судеб красноармейцев, захороненных на территории Советского Союза, или анализа безвозвратных потерь [1, 10, 13]. Современные российские историки в своих трудах рассматривали отдельные аспекты проблем советских воинских захоронений, касающиеся установления фронтовых судеб погибших воинов, проводили комплексные исследования теоретико-методологических и исторических основ сохранения российского (советского) военно-мемориального наследия $[9,11,12]$. Зарубежные исследователи советского периода уделяли внимание процессу увековечивания памяти о погибших в европейских странах воинах Красной армии, в основном, путем издания каталогов (книг) с поименными списками захороненных советских воинов [2, 19, 20]. Помимо этого за рубежом выпускались монографии, в которых раскрывалась 
не только история создания советских воинских некрополей и памятников, но и увековечивалась роль Красной армии и всего советского народа в победе над фрашизмом [3, 8].

В отличие от ранее написанных работ автором был изучен опыт деятельности официальных структур Советского Союза за рубежом по увековечению памяти о красноармейцах, погибших в годы Великой Отечественной войны при освобождении европейских стран. Исследование темы позволило выявить основные причины низкой эффрективности системы персонального учета потерь и проблем, сопровождавших процесс перезахоронения погибших в боях воинов; оценить масштаб работ по обустройству советских воинских захоронений и объем их финансирования; дополнить исторические факторы создания и сохранения советского военно-исторического и культурного наследия в Европе; раскрыть новые достоверные обстоятельства деятельности видных государственных должностных лиц и военачальников, а также различных офрициальных структур, принимавших действенное участие в формировании и реализации политики Советского Союза в области увековечения памяти о погибших советских воинах в европейских странах.

В научный оборот введен широкий спектр не публиковавшихся ранее архивных материалов государственных и военных структур Советского Союза периода 1944-1991 гг., представляющих большие возможности по изучению фрорм и содержания работы официальных советских структур за рубежом по увековечению памяти о красноармейцах, погибших в годы Великой Отечественной войны. Всего в исследовании использованы материалы 7 государственных и ведомственных архивов (ГА РФ, АВП РФ, РГВА, РГАЛИ, РГАНИ, РГАСПИ, ЦАМО РФ), 47 архивных фондов, 128 описей, 229 архивных дел. Более того, часть архивных материалов в ЦАМО РФ из фондов Центральной группы войск (11 дел) и Северной группы войск (17 дел) была рассекречена по запросу автора.

Современная методология исследования позволила использовать различные методологические подходы в изучении мемориальной проблематики $[6,15,16,17,18]$ и систему определенных исторических методов. В частности, общенаучные методы - обобщения, индукции и дедукции, анализа и синтеза, сравнения, системный; специально-исторические - историко-генетический, историко-системный, историко-типологический, историко-сравнительный и историко-динамический, изложенные и обоснованные в трудах российских ученых по теории методологии, историографии и библиографии $[4,5,7,14]$. Основные усилия при проведении исследования были направлены на изучение документального материала, посвященного персональному учету потерь и процессу погребения воинов Красной армии, погибших при освобождении европейских государств от нацизма, деятельности государственных и военных структур за рубежом по созданию советских воинских кладбищ и других объектов, на раскрытие форм межгосударственного сотрудничества Советского Союза с европейскими странами по сохранению памяти о погибших советских воинах.

В ходе исследования были получены следующие результаты:

1. Нормативные документы, принятые в ходе Великой Отечественной войны, не внесли ясности в персональный учет безвозвратных потерь, а сложившаяся специфика учета погибших в годы войны осложнила в настоящее время и без того непростую ситуацию, связанную с восстановлением имён 
погибших военнослужащих. Переход на новые формы личных учетных документов в 1941-1942 гг. снял с повестки дня вопрос об идентификации личности погибших военнослужащих. Органами военного управления были созданы специальные отделы, которые осуществляли контроль деятельности штабов по персональному учету потерь.

2. Процесс организации погребения погибших и создания на территории европейских государств воинских кладбищ имел следующие особенности: изначально не предполагалось осуществлять захоронения погибших на территории Германии; команды погребения испытывали определенные трудности, связанные с указанием точного места расположения могил военнослужащих, так как были слабо обеспечены топографическими картами европейских стран; согласование с местными властями мест для погребения погибших воинов, с учетом религиозных особенностей проживающего населения; стремление командования к организации крупных воинских кладбищ и недопущение одиночных мест захоронения. Существующая классификация воинских захоронений дополнена такими терминами, как захоронения полевых медицинских учреждений, оскверненное военное захоронение, уничтоженное военное захоронение, условное военное захоронение и захоронения союзнических армий.

3. В ходе Великой Отечественной войны красноармейцы не имели при себе надежного опознавательного средства, с помощью которого возможно определить личность погибшего при отсутствии у него документов. Количество безымянных останков, искажений и утрат биографических данных о погибших после проведения эксгумации и перезахоронения существенно возросло в силу ряда причин: нахождение останков погибшего в могиле без документов; несогласованные действия в процессе поиска тел погибших воинов и их перезахоронения; часть объективных данных о первичных воинских захоронениях утрачивалась, а их уточнение серьезно осложнялось; сотрудники строительных организаций и похоронных фирм могли неверно трактовать инфрормацию с первоначальных списков или с табличек на могилах, изменяя тем самым данные о погибших воинах.

4. Процесс укрупнения и сохранения советских воинских кладбищ на территории европейских стран развивался в течение пяти этапов. На первом этапе (май - осень 1945 г.) поисковые команды проводили проверку мест боев на предмет учета одиночных и братских могил и погребения незахороненных останков погибших на кладбища, указанные старшим начальником. Второй этап охватывает период с осени 1945 г. по осень 1946 г., в ходе которого рабочие команды воинских частей, инженерно-строительные части и местные строительные фрирмы оборудовали армейские и создавали гарнизонные воинские кладбища. Тем не менее ряд факторов помешал командованию качественно провести эти работы. На третьем этапе (осень 1946 г. - осень 1947 г.) организацию мероприятий по перезахоронению останков из одиночных могил, оборудованию новых воинских кладбищ, а также по привлечению частных фрирм осуществляли военные коменданты. После завершения работ кладбища передавались по акту местным органам власти для охраны, ухода и содержания. Четвертый этап охватывает период с августа 1948 г. по 1962 г., в ходе которого уполномоченные Совета министров Союза ССР по делам репатриации организовывали перезахоронение останков воинов, согласовывали работы по благоустройству могил, а также осуществляли сбор сведений о состоянии воинских 
кладбищ. При этом военные атташе выполняли функции контроля за сохранностью, а штабы группировок войск вели учет воинских захоронений. На пятом этапе (1963 г. - декабрь 1991 г.) военные атташе осуществляли сбор данных о красноармейцах, погребенных на воинских кладбищах, и вели учет мероприятий по улучшению содержания мест упокоения советских воинов. В штабах группировок советских войск в европейских странах осуществляли функции учета мест упокоения советских граждан.

5. В европейских государствах, освобожденных Красной армией от нацизма, были сооружены величественные мемориальные сооружения, воинские кладбища, объекты и памятники, увековечивающие память о погибших советских воинах. Для этого процесса характерны следующие особенности: в создании многих мемориальных комплексов участвовали советские специалисты во взаимодействии с местными властями, а также были задействованы местные мастера, строительные фирмы и производственная база; властные структуры и жители европейских государств участвовали в финансировании строительства памятников благодарности советским воинам; некоторые памятники на местах захоронений советских воинов стали предметом острой идеологической борьбы в стране или регионе; участие советских граждан в обустройстве мест упокоения своих родственников за рубежом носило не системный, а эпизодический характер.

6. В течение рассматриваемого периода (1944-1991 гг.) инициатива в процессе увековечивания памяти об освободительной миссии Красной армии в Европе часто принадлежала официальным структурам Советского Союза за рубежом. В то же время государственные и общественные институты в европейских странах применяли различные формы коммеморативных практик, позволяющих сохранять в целом доброжелательное отношение к советским воинским памятникам и заботливый уход за солдатскими могилами.

7. Процесс восстановления и сохранения советских воинских захоронений и памятников в странах Центрально-Восточной Европы имел характерные особенности: ответственность европейских государств за сохранность захоронений и памятников Красной армии не была юридически оформлена; содержание воинских захоронений и памятников финансировалось из бюджетов правительств и местных органов власти; совместная деятельность государств по восстановлению имен погибших красноармейцев была затруднена; активизация деятельности зарубежных общественных организаций началась с 60-х гг. XX столетия; военные атташе СССР осуществляли разностороннюю деятельность по вопросам увековечения памяти; со второй половины 80-х гг. началась очередная волна вандализма в отношении советского военномемориального наследия в европейских странах.

8. Классификация процесса увековечения памяти о советских воинах в странах Центрально-Восточной Европы позволяет проследить взаимосвязь между основными направлениями деятельности (содержанием работ) в данной сфрере и степенью участия различных официальных структур СССР и других государств на различных уровнях.

Практическая значимость исследования заключается в том, что научнотеоретические положения, выводы и практические рекомендации, сформулированные автором на основе проведенного исследования, могут быть творчески реализованы в ходе решения проблем по сохранению памяти о воинах Красной армии в современной России, научных и историко-мемориальных 
структурах, а также в учебно-воспитательном процессе, научно-исследовательской и военно-политической работе военно-учебных заведений Министерства обороны РФ. Представленное исследование дает всестороннее понимание процесса персонального учета погибших советских воинов, создания кладбищ и мемориалов в освобожденных Красной армией странах Европы. Его результаты можно использовать в ходе документально-поисковой работы по каталогизации советских (российских) воинских захоронений за рубежом, а также для уточнения персональных данных погибших красноармейцев и установления их имен на основе размещенных в электронных архивах документов периода Великой Отечественной войны. Оно будет полезно для специалистов Управления по увековечению памяти погибших при защите Отечества Министерства обороны РФ, а также для родственников воинов Красной армии, погибших и погребенных за пределами нашей страны, желающих самостоятельно изучить вопросы документального поиска места захоронения.

Результаты исследования могут быть использованы для дальнейшего изучения истории создания советских воинских кладбищ и памятников в странах Центрально-Восточной Европы. Целесообразно продолжать работы по следующим направлениям: укрепление контактов и оказание различных форм поддержки общественным структурам и частным лицам, способствующим сохранению российского военно-исторического наследия за рубежом; проведение исследовательских работ с документами в архивах и размещенными в открытом доступе сети Интернет, с целью возврата из небытия имен погибших красноармейцев; рассекречивание документов послевоенного времени в архивах, имеющих отношение к созданию и обустройству воинских некрополей и объектов, расположенных в странах Европы; выполнение НИР, разработка монографий, организация конференций по вопросам создания и сохранения советских воинских захоронений в том или ином европейском государстве, например, Германии, Польше, Чехии и др.

\section{Литература}

1. Бушуева О.Ю. Безвозвратные людские потери Куйбышевской области в годы Великой Отечественной войны 1941-1945 гг.: автореферат дис. ... канд. ист. наук. Казань, 2010. 24 c.

2. Захоронения советских граждан на территории Вольной земли Саксония. Объединение Саксонские мемориалы в память жертв политического террора. Дрезден, 2008. 335 c.

3. Кёпштайн X. Советские памятники в Берлине. М.: СВР-Медиа, 2010. 288 с.

4. Ковальченко И.Д. Методы исторического исследования. М.: Наука, 2003. 485 с.

5. Мартюшов Л.Н. Основы теории и методологии истории. М.: Екатеринбург, 2016. $182 \mathrm{c}$.

6. Мегилл А. Историческая эпистемология. М.: Канон+, 2007. 480 с.

7. Менщиков И.С. Введение в методологию истории. М.: Курганский гос. ун-т, 2015. 208 c.

8. Памятник советскому Воину-освободителю в Трептов-парке. Прошлое и настоящее памятника-кладбища в Берлине. Берлин, 1981. 168 с.

9. Рубин В.А. Военно-мемориальное наследие как феномен российской культуры: теоретические и исторические аспекты. Челябинск: ЧГИК, 2019. 351 с.

10. Садовников С.И. Источники и методы поиска, установления имен и судеб воинов, оставшихся на полях сражений Великой Отечественной войны: дис. ... канд. ист. наук. М., 1999. 230 с.

11. Садовников С.И. Чтоб не распалась связь времен...: опознаны по боевым наградам. М.: [Б.и.], 2005. 296 с. 
12. Садовников С.И. «Война участвует во мне...». Комплексные поисковые исследования как основа реконструкции биографий участников Великой Отечественной войны 1941-1945 гг. М.: Золотой теленок, 2017. 320 с.

13. Скворцова Л.Г. Безвозвратные потери уроженцев Республики Мордовия в годы Великой Отечественной войны: автореф. дис. ... канд. ист. наук. Саранск, 2004. 24 с.

14. Теория и методология исторической науки: терминол. слов / отв. ред. А.О. Чубарьян. М.: Аквилон, 2014. 575 с.

15. Федорова М. М. История/память: «трудная» дилемма // История философиии. 2018. T. 23, № 1. С. 108-121.

16. Франция-память / П. Нора, М. Озуф, Ж. де Пюимеж, М. Винок. СПб.: Изд-во С.-Петерб. ун-та, 1999. С. 17-50.

17. Хальбвакс M. Коллективная и историческая память [Электронный ресурс]// Неприкосновенный запас. 2005. № 2 (40-41). URL: https://magazines.gorky.media/nz/ 2005/260222 (дата обращения: 10.01.2020).

18. Чеканцева З.А. Коллективная память и история // Преподаватель XXI век. 2015. № 4. C. 229-239.

19. Akitet vissyavartak... Szovjet hosi halottak Heves megyeben (Кого не дождались... Советские солдаты, павшие смертью храбрых в области Хевеш). EgerЭгер, 1985. $90 \mathrm{~s}$.

20. Рamiec - Память / сост. Я. Пшимановский, Х. Прокопчук, Р. Мурани; пер. с пол. К. Казакевич. Варшава: Dom Slova Polskiego, 1987. Ч. 1, 2.

ОБЕРНИХИН ЕВГЕНИЙ АНАТОЛЬЕВИЧ - дОцент кафедрЫ гуманитарныХ и социально-экономических дисциплин, Московское высшее общевойсковое командное училище, Россия, Москва (obernikhin2013@yandex.ru; ORCID: https://orcid.org/0000-0003-3692-3651).

\section{Evgeny A. OBERNIKHIN \\ PERPETUATING THE MEMORY OF SOVIET SOLDIERS \\ WHO PERISHED DURING THE LIBERATION OF EUROPEAN COUNTRIES \\ FROM NAZISM DURING THE GREAT PATRIOTIC WAR (1944-1991): THE RESULTS OF THE STUDY}

Key words: the Great Patriotic War, the Red Army, Central-Eastern Europe, memory, research results, Soviet military cemeteries.

Comprehensive studying the experience of state and military structures in preserving and care of military cemeteries and places of memory about the heroic actions of the Red Army outside Russia, is gaining more and more theoretical significance and practical value. The purpose of this article is to summarize the results of the study dedicated to perpetuating the memory of Soviet soldiers who perished when liberating European countries from Nazism during the Great Patriotic War (chronology of events in 1944-1991). There are no special scientific works devoted to this topic that comprehensively consider the activities of the official structures of the Soviet Union abroad. The methodological basis of the research is the modern theory of society cognition, based on the concept of universal connections in its socio-economic, political and cultural life, and the dialectical approach to the analysis of social phenomena. The author analyses various aspects of the problem taking into account the immediate historical situation, reveals objective patterns that determined the goals and content of the process of preserving the memory of fallen Soviet soldiers, he studies the activities of the official structures of the Soviet Union abroad to perpetuate the memory of the Red Army soldiers who perished during the Great Patriotic War 
when liberating European countries from Nazism. In the course of the study, the author solved a number of tasks: transformation in the order of personal casualty records in the Red Army was investigated; the features of organizing the process of burial of the deceased and creation of military cemeteries in the territory of European states were established, as well as the existing classification of military graves was confirmed; the reasons for the large-scale loss of names of Red Army soldiers who died when liberating European countries from Nazism were determined; the main stages of the process of consolidation and preservation of Soviet military cemeteries in the territory of European countries were determined; the process of creating memorial structures and objects in Central and Eastern Europe was analyzed and its features were established; implementation of commemorative practices which formed in the Soviet times the historical memory about Red Army's liberation mission in European countries; the author defines the peculiarities of inter-state cooperation on the issues of restoration and preservation of Soviet military graves and monuments in European countries; he defines the classification of the process of perpetuating the memory of Soviet soldiers in the countries of Central and Eastern Europe. The study performed suggests that it was during the enlargement of the Soviet military cemeteries after the war that a large-scale loss of the names of the fallen Red Army soldiers occurred. The process of creating memorials and arranging military necropolis in the European countries had a systematic character. The Soviet Union used various commemorative practices, with the help of which the historical memory of the Red Army's liberation mission in Europe was formed.

\section{References}

1. Bushueva O.Yu. Bezvozvratnye lyudskie poteri Kuibyshevskoi oblasti v gody Velikoi Otechestvennoi voiny 1941-1945 gg.: avtoreferat dis. ... kand. ist. nauk [Irretrievable human losses of Kuibyshev region during the Great Patriotic War, 1941-1945. Abstract of Cand. Diss.]. Kazan, 2010, 24 p.

2. Zakhoroneniya sovetskikh grazhdan na territorii Vol'noi zemli Saksoniya. Ob"edinenie Saksonskie memorialy $v$ pamyat' zhertv politicheskogo terrora [Graves of Soviet citizens on the territory of the Free State of Saxony. United Saxon memorials to the victims of political terror]. Drezden, 2008, $335 \mathrm{p}$.

3. Kepshtain Kh. Sovetskie pamyatniki $v$ Berline [Soviet monuments in Berlin]. Moscow, SVR - Media Publ., 2010, 288 p.

4. Koval'chenko I.D. Metody istoricheskogo issledovaniya [Methods of Historical Research]. Moscow, Nauka Publ., 2003, 485 p.

5. Martyushov L.N. Osnovy teorii $i$ metodologii istorii [Fundamentals of Theory and Methodology of History]. Moscow, Ekaterinburg, 2016, 182 p.

6. Megill A. Istoricheskaya epistemologiya [Historical Epistemology]. Moscow, Kanon+ Publ., 2007, 480 p.

7. Menshchikov I.S. Vvedenie $v$ metodologiyu istorii: uchebnoe posobie [Introduction to the Methodology of History: Textbook]. Moscow, Kurgan University Publ., 2015, 208 p.

8. Pamyatnik sovetskomu Voinu-osvoboditelyu v Treptov-parke. Proshloe $i$ nastoyashchee pamyatnika-kladbishcha $v$ Berline. [Monument to the Soviet Soldier-Liberator in Treptow Park. The past and present of the cemetery monument in Berlin]. Berlin, 1981, $168 \mathrm{p}$.

9. Rubin V.A. Voenno-memorial'noe nasledie kak fenomen rossiiskoi kul'tury: teoreticheskie $i$ istoricheskie aspekty [Military memorial heritage as a phenomenon of Russian culture: theoretical and historical aspects: monograph]. Chelyabinsk, 2019, $351 \mathrm{p}$.

10. Sadovnikov S.I. Istochniki i metody poiska, ustanovleniya imen $i$ sudeb voinov, ostavshikhsya na polyakh srazhenii Velikoi Otechestvennoi voiny: dis. ... kand. ist. nauk [Sources and methods of search, establishment of names and destinies of soldiers who remained on the battlefields of the Great Patriotic War. Cand. Diss.]. Moscow, 1999, 230 p.

11. Sadovnikov S.I. Chtob ne raspalas' svyaz' vremen...: opoznany po boevym nagradam [Not to break the "connection» of times...: identification by military decorations]. Moscow, 2005, 296 p. 
12. Sadovnikov S.I. "Voina uchastvuet vo mne...». Kompleksnye poiskovye issledovaniya kak osnova rekonstruktsii biografii uchastnikov Velikoi Otechestvennoi voiny 1941$1945 \mathrm{gg}$. ["War participates in me...». The complex research study as a basis for reconstruction of biographies of participants of the Great Patriotic War of 1941-1945]. Moscow, Zolotoi telenok Publ., 2017, 320 p.

13. Skvortsova L.G. Bezvozvratnye poteri urozhentsev Respubliki Mordoviya v gody Velikoi Otechestvennoi voiny: avtoreferat dis. ... kand. ist. nauk [Irretrievable losses of natives of the Republic of Mordovia during the Great Patriotic War. Abstract of Cand. Diss.]. Saransk, 2004, 24 p.

14. Chubar'yan A.O., ed. Teoriya i metodologiya istoricheskoi nauki: terminol. slov. [Theory and methodology of historical science: terminology of words]. Moscow, Akvilon Publ., 2014, 575 p.

15. Fedorova M. M. Istoriya/pamyat': «trudnaya» dilemma [History/memory: A «difficult» dilemma]. Istoriya filosofii, 2018, vol. 23, no. 1, pp. 108-121.

16. Nora P., Ozuf M., de Pyuimezh Zh., Vinok M. Frantsiya-pamyat' [Memory]. St. Peterburg, 1999, pp. 17-50.

17. Khal'bvaks M. Kollektivnaya $i$ istoricheskaya pamyat' [Collective and historical memory]. Neprikosnovennyi zapas, 2005, no. 2(40-41). Available at: https://magazines.gorky.media/nz/2005/260222 (Access Date: 2020, Jan. 10).

18. Chekantseva Z.A. Kollektivnaya pamyat' $i$ istoriya [Collective memory and history]. Prepodavatel' XXI vek, 2015, no. 4, pp. 229-239.

19. Akitet vissyavartak... Szovjet hosi halottak Heves megyeben (Kogo ne dozhdalis'... Sovetskie soldaty, pavshie smert'yu khrabrykh $v$ oblasti Khevesh) [Who wasn't waited ... Soviet soldiers who died the death of the brave in the region of HHeve]. Eger-Eger, 1985, $90 \mathrm{p}$.

20. Pshimanovskii Ya., Prokopchuk Kh., Murani R., comps. Pamiec - Pamyat' [Memory]. Varshava, Dom Slova Polskiego, 1987, part 1, 2.

EVGENY A. OBERNIKHIN - Associate Professor, Department of the Humanities and Socio-Economical Subjects, Moscow Higher Combined-Arms Command School, Russia, Moscow (obernikhin2013@yandex.ru; ORCID: https://orcid.org/0000-00033692-3651).

Формат цитирования: Обернихин Е.А. Увековечение памяти о советских воинах, погибших при освобождении европейских стран от нацизма в годы Великой Отечественной войны (1944-1991): результаты проведенного исследования // Исторический поиск. - 2021. - T. 2, № 2. - C. 69-77. DOI: 10.47026/27129454-2021-2-2-69-77. 